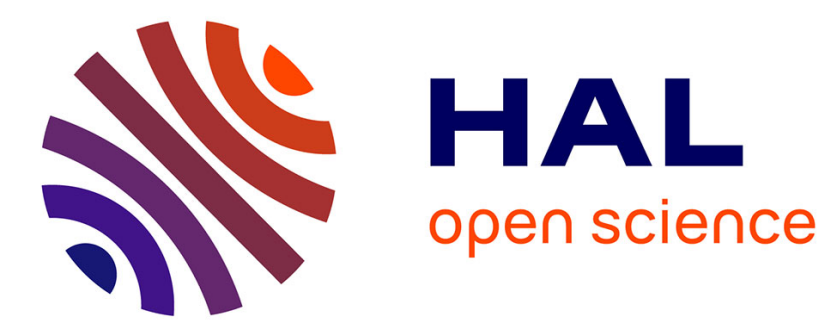

\title{
Spinocerebellar ataxia type 15: diagnostic assessment, frequency, and phenotypic features
}

\author{
Matthis Synofzik, Christian Beetz, Claudia Bauer, Michael Bonin, Elena \\ Sanchez-Ferrero, Tanja Schmitz-Hübsch, Ullrich Wuellner, Thomas Nägele, \\ Olaf Riess, Ludger Schöls, et al.
}

\section{To cite this version:}

Matthis Synofzik, Christian Beetz, Claudia Bauer, Michael Bonin, Elena Sanchez-Ferrero, et al.. Spinocerebellar ataxia type 15: diagnostic assessment, frequency, and phenotypic features. Journal of Medical Genetics, 2011, 48 (6), pp.407. 10.1136/jmg.2010.087023 . hal-00612823

\section{HAL Id: hal-00612823 https://hal.science/hal-00612823}

Submitted on 1 Aug 2011

HAL is a multi-disciplinary open access archive for the deposit and dissemination of scientific research documents, whether they are published or not. The documents may come from teaching and research institutions in France or abroad, or from public or private research centers.
L'archive ouverte pluridisciplinaire HAL, est destinée au dépôt et à la diffusion de documents scientifiques de niveau recherche, publiés ou non, émanant des établissements d'enseignement et de recherche français ou étrangers, des laboratoires publics ou privés. 


\section{Reply to the Editor and the Reviewers}

Dear Prof. Polychronakos,

Thank you for the expedited review process and for giving us the opportunity to revise and resubmit our manuscript. The comments of the editors and the reviewers' comments were valuable for optimizing our manuscript. Please find attached a largely rephrased submission of the manuscript and a detailed response to the points raised by you and each of the two reviewers.

Sincerely, Ludger Schöls

Response to the Editor:

„Specifically, the superiority of MLPA over qPCR should be better documented, per the comments of one of the reviewers."

Reply: After weighing all valuable comments of the reviewers we decided to remove our main qPCR data from the manuscript, following in particular the suggestion of reviewer \#1. This decision was not easy as we have invested a lot of resources in the qPCR part. However, given the particularities of our DNA sample which includes partially old and degraded DNA from a continuous series of patients with dominant ataxia collected over almost 15 years, a direct comparison between qPCR and MLPA does indeed not seem fair and might lead to unjustified conclusions, as pointed out by the reviewers. Certainly, the challenges of difficult samples (partially old and degraded DNA) and large diagnostic demands (ideally measuring all exons at once) favor multiplexed diagnostic approaches like MLPA. We have learned that this fact is too trivial to exemplify with our questionable qPCR data. It has not been our intention to question qPCR for gene dosage analysis as a method itself, and we are convinced - like both reviewers suggest - that there is no intrinsic technical superiority of MLPA compared to qPCR. Thus, all remaining questions were carefully answered with a special focus on the validity of our MLPA assay, without comparison to qPCR.

Response to reviews:

REVIEWER 1:

1. My main criticism relates to the justification for including the qPCR data. Clearly this particular qPCR assay is unsuitable and I don't see what useful information it adds. It may give the unfair impression that no qPCR assay would be suitable.

Reply: We are grateful for this very convincing remark. For the reasons stated above, we omitted the qPCR data.

2. Page 5: The MLPA probe sequences should be provided as supplementary data to allow others to replicate the findings."

Reply: We now provide the MLPA probe sequences, reference MLPA probes for other genomic regions and size distribution of MLPA probes in the ITPRI assay in supplementary table 1. Additionally, we provide an annotation of the MLPA probes in the revised figure 2. 
3. Page 7: There is no presentation of MLPA data. Given that this is an in-house developed assay, there needs to be some evidence that the MLPA assay is valid other than using the array method (which wasn't used on cases giving a normal MLPA result). Figure 1 is fine as a summary but I suggest presenting supplementary data or even presenting a single case in a figure including error bars indicating the normal and abnormal ranges and p-values for each deletion."

Reply: We now provide MLPA data from control subjects including the normal variation, exemplary MLPA data of a single case compared to controls, means and standard errors of the means (in an extension of Figure 1) and quantitative MLPA data of all subjects in a table format (supplementary table 2)..

4. Some description of the SNP coverage of the ITPR1 exons would be useful other than the total number. Any deletion containing fewer than 10 SNPs would be difficult to detect. How many SNPs are contained in each of the deleted cases?"

Reply: A new table (table 1) is introduced detailing deletion sizes and the number of SNPs contained in each SCA15 deletion.

5. Where is F06 data in Figure 2?"

Reply: F06 DNA was too old for accurate SNP array measurements (technical failure). A comment is given in table 2 description.

6. "More detail on breakpoints within SUMF1 is needed; Figs 1 and 2 are very uninformative on this. I take it that there was only array data on SUMF1; is the SNP coverage adequate to determine the SUMF1 breakpoints with confidence?"

Reply: Details about the algorithms used to qualify CNVs have been included in the methods section. As far as possible the breakpoints in SUMF1 have been included in figure 2.

7. "“the third mutation (better say deletion).....did not include the 3 prime of the ITPR 1 gene' - please state which case this refers to. Furthermore, no deletion appears to include the 3 prime end."

Reply The deletion in F48 does not include the 3 prime. We added the family codes to the deletions to allow a better identification and phrased the sentences more clearly.

8. "Fig 2 should be redrawn to focus more on the ITPR1 and SUMF1 regions. Most of the figure as it stands is wasted space.

Reply: We have completely changed figure 2, now focussing more on ITPRI and SUMF 1 regions.

9. "Page 8, last sentence, first para: this is a repeat of what has been stated earlier in the paragraph."

Reply: To avoid this redundancy, we omitted the statement earlier in the paragraph.

10. "Page 10: the acronym ADCA needs explained."

Reply: The acronym "ADCA" (=autosomal-dominant cerebellar ataxia) has been replaced by the acronym SCA (=autosomal-dominant spinocerebellar ataxia), which is explained in the introduction and used throughout the manuscript.

11. "The discussion of balancing the resources against the accuracy of the test is good. Perhaps it is worth adding that for individual tests versus testing a cohort, a microarray approach would be best."

Reply: We added this statement to the discussion. 
12. "The statement that MLPA is 'superior' to qPCR shouldn't be made. Without wanting to offend, qPCR is not the easiest of techniques and in the hands of another laboratory might be satisfactory."

Reply: The reviewer is certainly right. As already indicated in response to the first remark, the qPCR failures observed in our study were probably indeed attributable not to intrinsic deficits of qPCR, but to low DNA quality. Thus, a fair comparison between both methodologies does not seem possible, and we therefore omitted the qPCR data from the manuscript.

13. 'Grammatical corrections: Page 5: 'qPCR rather 5' ITPR1.....' delete rather; Page 6: 'where' should be "were'."

Reply: We corrected both errors.

\section{REVIEWER 2:}

14. The superiority of MLPA vs qPCR from a technical point of view is not proved to me. In particular the authors need to improve the methods section, and verify that qPCR failures are not attributable to variants in case of a suspected deletion, technical problems or bad DNA quality."

Reply: We completely agree that DNA quality is a critical factor for quantitative measurements, and the qPCR failures might indeed be attributable to low DNA quality, but not deficits in qPCR per se. Therefore, we omitted the qPCR data from the manuscript as stated above.

15. Numeric values are given for qPCR only in table 1, while they should be shown for both with standard deviations. Samples test both with qPCR and MLPA need to be repeated and DNA checked in case of strange results deletion/duplication in the same sample, values unexpected), but it is unclear if they were. Sample F29-051329 and F18-SCA1258 have strange values in qPCR that may be due to bad DNA quality. What about MLPA in these samples, values are missing? Sample F29-031401 results may be explained by two polimorphisms in heterozygosis in the tested exons, that need to be sequenced. Reply: We omitted the qPCR data from the manuscript. Numerical values are now given for MLPA, including standard deviations (figure 1; supplementary table 2). For sample F48051329 (we think there was a type-o from the reviewer's side as we did not have a sample F29-051329; he probably intended to refer to F48-051329 as this sample had a falsely high value in qPCR), MLPA yielded decreased values, indicating a deletion (see current Figure 1 and supplementary table 2). For sample F18-SCA1258 (which was a false positive in qPCR), MLPA yielded normal results. Likewise, sample F29-031401 (which was also a false positive in qPCR) also yielded normal results in MLPA. In the present version of the manuscript these parts have been removed.

16. Figures do not emphasize results obtained and need a profound and careful revision." Reply: We profoundly revised all our figures.

17. Table 1. qPCR data need to be expressed with a standard deviation, telling how many experiments for each exon were performed. The complete set of exons tested can be shown, at least in supplementary. The mean for different exons is a nonsense, because a deletion can be partial." 
Reply: See response to comment\# 25 for qPCR methodology. The following table provides standard deviations of qPCR data (without means, as these are indeed not needed, as pointed out by the reviewer). This table was omitted in the current version of the manuscript:

Table 1:

\begin{tabular}{|c|c|c|c|}
\hline & ID & Exon 3 & Exon 6 \\
\hline \multirow{5}{*}{ SCA15 } & $\begin{array}{l}\text { F06-SCA0142 = } \\
\text { F06-III-8 }\end{array}$ & Failed & $0.542 \pm 0,146$ \\
\hline & $\begin{array}{l}\text { F34-040232= } \\
\text { F34-III-2 }\end{array}$ & $0.559 \pm 0,116$ & $0.379 \pm 0,069$ \\
\hline & $\begin{array}{l}\text { F49-050994 = } \\
\text { F49-III-3 }\end{array}$ & $0.388 \pm 0,108$ & $0.583 \pm 0,297$ \\
\hline & $\begin{array}{l}\text { F39-051019= } \\
\text { F39-III-4 }\end{array}$ & $0.403 \pm 0,115^{\text {(a) }}$ & $0.645 \pm 0,328$ \\
\hline & $\begin{array}{l}\text { F48-051329= } \\
\text { F48-III-7 }\end{array}$ & $0.645 \pm 0,293$ & $1.403 \pm 0,293^{(b)}$ \\
\hline \multirow{2}{*}{ false-positives } & F18-SCA1258 & $0.152 \pm 1,023^{\text {(a) }}$ & $1.600 \pm 0,391$ \\
\hline & F29-031401 & $0.450 \pm 0,089^{\text {(a) }}$ & $0.575 \pm 0,109^{(a)}$ \\
\hline
\end{tabular}

qPCR data points represent mean relative gene dosage changes normalized to reference gene dosages (see method section). In three samples a total of four false positive measurements was observed (indicated by ${ }^{(a)}$ ): F39-051019 (exon 1 qPCR values were reduced, whereas MLPA demonstrated normal values for promoter and exon 2 probes); F18-SCA1258 (one extremely reduced data point in exon 1; the data point in exon 4 was normal) and F29-031401 (two apparently consistent measurements in exon 1 and 4). Neither MLPA analysis nor high density SNP array analysis (not performed for sample F18-SCA1258) yielded suspicious signals in these three samples. Moreover, qPCR analysis (and high density SNP array analysis) failed for exon 1 in sample F06-SCA0142 due to bad DNA quality (this sample had been stored for almost 12 years) and sample F48-051329 was normal for exon 4 (false negative; indicated by ${ }^{(b)}$ ).

18. "Note to table 1 contain comments that should not be here. Notes in tables do not contain comments on the results. Put only the relevant information to read values, leave comments in the results section."

Reply: The former table 1 is now completely removed.

19. "Figure 1. The real MLPA data, or at least the calculations need to be showed. A more elegant scheme of the gene and the tested exon should be provided. See for instance the figure reported in Ganesamoorthy et al., 2009 (reference 6). In this paper it is clear that also MLPA has a great variability. This figure may contain a second panel with the data of table 1 . The location of the regions tested by qPCR and MLPA could be given in a unique scheme." Reply: We now provide detailed MLPA data in figure 1 and, in particular, in supplementary table 2. Calculations are performed as already reported earlier (Schüle et al., 2009; Neurogenetics), this reference is referred to in the manuscript. A clarified scheme of the genomic region with coordinates of all deletions, MLPA and qPCR locations is now given in figure 2.

20. "Figure 2. It is important to clearly show the extension of the deletions found. I propose to zoom the figure to a region more close to ITPR1 gene. Add for instance a double arrow to each SNP array plot with the extension of the deletion. Specify, the likely minimal-maximal extension of the deletion in $\mathrm{Kb}$ for each deletion found, defining the breakpoints from the SNP-array probes. It is never cited which are the involved exons in ITPR1 and SUMF1 (when 
involved).The scheme of the genes, below needs to be prepared in a more detailed way and not only copied and past from Ensembl. Indicate better the positions and the hgs used; where are centromere and telomere located? What is the scale on the left? What are the shadows (specify in the legend)."

Reply: Figure 2 has been modified according to the suggestions of the reviewer. The extension of the deletions and involved exons as determined by SNP array are now given in table 1.

21. "Other points: Introduction, page 4, line 7. The authors cite SCA20 and SCA30 as "private" genes. Because these loci do not have a gene yet, and large screenings could not be done, they cannot be considered "private". Bibliography citations are lacking for loci/genes not reported in reference 1 (Schols et al., 2004)".

Reply: We are grateful for this remark. SCA20 and SCA30 are now no longer referred to as "private genes" and we added bibliography citations that were lacking so far.

22. "Introduction, page 4, line 9. "less common SCA subtypes": again this is an assumption not supported by genetic screenings. Actually, the conclusions of the paper show that SCA15 is not so rare. I would suggest to change into "recently identified".

Reply: This is a good suggestion, which we adopted in the new version of the manuscript.

23. "Introduction, page 4, line 13 and throughout the texts. Numbers in the papers are generally in letters up to ten, and numerals from $11 \mathrm{on}$. Exception is at the beginning of a sentence (see page 5 line 8, "50\%" should be "Fifty percent"."

Reply: We revised the manuscript accordingly.

24. "Page 5, molecular genetics analyses, line 3. I do not understand the sentence: "For both MLPA and qPCR rather 5' ITPR1 targets were selected". Please reformulate."

Reply: We rephrased this sentence as follows: MLPA targets were selected to cover especially 5' portions of the ITPRI gene due to the fact that all deletions reported previously included at least exons 1 to 10.

25. "Page 5. Supplementary figure 1 is never cited in the text. It could be inserted in materials and methods. Page 6 line 3. Analysis of MLPA data, and below. It would be easier for the reader to find in supplementary materials all the information needed to set up the methods described, including primers, probes, PCR conditions, and methods used in the analysis of data (MLPA, and qPCR). It is not reported even the mix used for qPCR. Was a probe used or SYBR green for qPCR?"

Reply: All details about the MLPA probes and qPCR primers are now given in supplementary table 1. Most parts of the qPCR results were now omitted from the manuscript. We only use qPCR to address the effect of the unusual preservation of the 5' end in one SCA15 family. More details on the qPCR method were added to the "material and methods" section.

26. "Page 6. Cite the reference accession number of the ITPR1 gene used. Numbering of exons can change with time.

Reply: The reference sequence (NM_001099952) is now given in supplementary table 1.

27. "Page 6, line 21. "More than 120 SNPs...": the authors are too generic. They do know how many, and their location."

Reply: More precise numbers of SNPs are now provided in the method section and table 1. 
28. "Page6, line 15. "For nine index patients...": this part is not materials and methods and should be put in results. Because the authors emphasize the superiority of MLPA on qPCR I think that more details are needed. Which gene was used as reference (BCMA, SDC4, B2MG, all three?)? What the authors did when a sample had a suspected deletion/duplication? Did they repeat the test, and how many times? It is important to run a group of controls to verify the variability of the gene dosage in normal subjects; was this done? If not, how the authors define the threshold of $70 \%$ for deletions? Was DNA quality / degradation verified when a sample was found as a false positive? For qPCR and MLPA standard deviations need to be shown."

Reply: For qPCR methodology, please refer to the response to comment \#25.

Standard errors of the means (SEM) for MLPA are now given in figure 1.

29. "Page 6 and throughout the text. Check all gene names are in italics (see for example lines 11 and 14)."

Reply: The manuscript has been revised accordingly.

30. Page 6 line 15. "qPCR signals were augmented": it is necessary to be more specific; a value and a standard deviation need to be provided. How many times the experiments were done?"

Reply: See comment 17 and comment 25.

31. "Page 6 line 17, and throughout the text. "exemplarily" should be changed. The entire paragraph can be simplified. The authors tested seven patients with a possible deletion and two out of nine patients with a possible duplication. I would not add further explanations that may results in a circular reasoning."

Reply: "Exemplarily" was omitted with the main qPCR data from the manuscript.

32. Page 6 line 20. "represented by eight data points". The points tested in ITPR1 are reported to be seven in page 5, and in legend to figure 1 .

Reply: The correct number is indeed seven. We corrected the error on page 6.

33. "ID numbers are not homogeneous throughout the text and in figures. Sometimes a subject is cited with its Family-DNA code, sometimes with the number in the pedigree." Reply: This is a valid comment. We now used the subject codes from the pedigrees (supplementary figure) throughout the manuscript and omitted DNA-codes.

34. "Page 7 line 18. "The deletion spanned approximately": is it possible to define the exons involved?"

Reply: Details of deletions are now presented in table 1. Its relation to the SUMF1 gene is shown in the revised figure 2 as far as the accuracy of the SNP array approach allows.

35. "Page 7 line 19. "The smallest deletion..." change to "The smallest deletion was found in patient F49, and partly ...". Next line "which was slightly larger in the ITPR1 gene". The sentences need to be reformulated, with a more precise value. I would advise the authors not to use generic terms."

Reply: We are very grateful for this remark. We modified the paragraph according to this suggestion and tried to omit generic terms as far as possible.

36. "Page 7 last sentence: "This finding, which could be confirmed...". I think is "This finding, which was confirmed...".

Reply: We corrected the sentence accordingly. 
37. "qPCR results showing a possible deletion may be explained by a variant in that exon. The exon needs to be sequenced."

Reply: The respective qPCR data are now omitted.

38. "Page 8, line 3. The authors are assuming MLPA provided accurate results. This is a circular reasoning. In the discussion they conclude MLPA give more reliable results, but it seems because the authors already though it was more reliable."

Reply: MLPA showed different deletions for different families, but yielded highly reliable results within each family, thus indicating its reliability. All ITPRI deletions detected by MLPA were confirmed by an independent SNP array approach and also MLPA estimates of minimal deletion sizes were confirmed by SNP array. This indicates the validity of our MLPA assay. However, we admit that we cannot exclude false negative findings with our MLPA assay, as stated clearly in the discussion. Such findings, however, would even increase the relatively high frequency of SCA15 in patients with unexplained SCA, which we report in our study.

39. Page 9. "The five families .... for genetic testing". This part can be simplified. The discussion can be shortened."

Reply: The discussion has been shortened accordingly.

40. An possible anticipation is visible in their families in supplementary figure 1 . it is curious anticipation in SCA15 was recently described by Di Gregorio et al., 2010. Is there a difference between different deletions, and in particular when SUMF1 is deleted?" Reply: This is a very interesting question. However, given the fact that SCA15 starts very slowly - and can even start "unnoticed" (as pointed out for two of our subjects)- the impression of "anticipation" might simply be due to the fact that current generations are more sensitive to even subtle coordination changes, which had not been paid attention to in their parental generations. We strongly believe that only larger patient cohorts and in particular prospective studies, starting early in the life course of asymptomatic SCA15 riskpersons, can truly investigate whether there is an anticipation effect in SCA 15 or not. Concerning our families, only in family F34 SNP arrays of several affected were available. Here, differences in deletions vary by a maximum of $6 \mathrm{SNPs}(16 \mathrm{~kb})$ and therefore do not allow meaningful correlations with age of onset.

41. Discussion. Page 9, line 2. "This findings surmounts...". Check the English of this sentence."

Reply: We replaced the term "surmounts" by "exceeds".

42. "Page 10, line 20. "So far, single aminoacid changes...". A single a.a. change is reported in one patient with a unknown significance (p.P1059L, reference 4). The other two cited are a synonymous change and a SNP. Erase the latter two."

Reply: We are grateful for this remark. We erased the latter two.

43. "Legends to the figures. Fig.1. "seven localizations" change for instance to "seven regions" $\square$. Check: "Red bars visualize the least length". At the end indicate the name of the five families among brackets."

Reply: We corrected the errors and indicated the names of the five families. 
44. Fig.2. Title:Change to "Copy number variation..." .First sentence change to: "Copy number ....SCA15 region for three sample of family F34 (...), F39-051019, F48-0551329, and F49-050994

are shown." Erase next line. "F06-SCA0142 ..." $\square$ and last line. These sentences are not useful here, leave this comment in materials and methods. Additionally ...." change to "The sample F29-031401 was suggestive for a heterozygous ITPR1 gene deletion based on qPCR results, but normal in MLPA."

Reply: The figure legend has been modified accordingly. 
Videos are part of ms

\title{
Original Article
}

\section{Spinocerebellar ataxia type 15:}

\section{diagnostic assessment, frequency, and phenotypic features}

\author{
Matthis Synofzik, M.D ${ }^{1,6^{*}}$; Christian Beetz, $\mathrm{PhD}^{2^{*}}$, Claudia Bauer ${ }^{3}$; Michael Bonin, $\mathrm{PhD}^{3}$, \\ Elena Sanchez-Ferrero ${ }^{2}$, Tanja Schmitz-Hübsch, M.D. ${ }^{4}$; Ullrich Wüllner, M.D. ${ }^{4}$; Thomas \\ Nägele, MD ${ }^{5}$, Olaf Riess, M.D. ${ }^{3}$; Ludger Schöls, M.D. ${ }^{1,6 \#, ~ P e t e r ~ B a u e r, ~ M . D . ~}{ }^{3}$
}

1) Department of Neurology, Hertie-Institute for Clinical Brain Research, University of Tübingen, Germany

2) Institute of Clinical Chemistry, University of Jena, Germany

3) Dept. of Medical Genetics, University of Tübingen, Germany

4) Dept. of Neurology, University of Bonn, Germany

5) Dept. of Neuroradiology, University of Tübingen, Germany

6) German Centre of Neurodegenerative Diseases (DZNE), University of Tübingen, Germany

*Both authors contributed equally to this study.

\footnotetext{
\# Corresponding author: Dr. Ludger Schöls, Clinical Neurogenetics, Department of Neurology and Hertie-Institute for Clinical Brain Research, University of Tübingen, Hoppe-Seyler-Str. 3, D 72076 Tübingen, Germany Fon: +49 707129 80445; Fax: +49 7071294839 ludger.schoels@uni-tuebingen.de
}

Word count: $\quad 2427$ words excluding abstract

Running title: Diagnostic assessment, frequency and, phenotype of SCA 15 
Figures: $\quad 3$

Tables: $\quad 3$

Supplementary Material: 2 videos, 1 figure, 2 tables

Abbreviations: $\quad \mathrm{CNV}$, copy number variation analysis; DRPLA, dentatorubral-

pallidoluysian atrophy; HMM, Hidden Markov Model; ITPR 1, inositol

1,4,5-triphosphate receptor, type 1; MLPA, multiplex ligation-

dependent probe amplification; SCA, autosomal-dominant

spinocerebellar ataxia; SNP, single nucleotide polymorphism;

Study funding: supported by the European Union (EUROSCA consortium; LSHM-CT-2004503304)

\section{Competing Interest:}

None to declare. 


\section{Abstract}

Background: To guide time- and cost-efficient analyses of the increasing number of autosomal-dominant spinocerebellar ataxia genes (SCAs), more information about frequency distributions, phenotypic characteristics and optimal diagnostic strategies is warranted.

Objective: To assess the prevalence and phenotypic spectrum of SCA15 and to confirm multiplex ligation-dependent probe amplification (MLPA) as a robust and efficient strategy for routine molecular diagnosis.

Methods: Fifty-six German SCA families negative for common repeat expansions were screened for ITPRI deletions by MLPA. Samples with conspicuous MLPA data were additionally assessed by high-density SNP-array to confirm MLPA results and further determine the size of deletions. The phenotype of patients harbouring ITPRI deletions was characterized by standardized clinical, electrophysiological and imaging assessment.

Results: SCA15 accounted for 8.9\% (5/56) of SCA families negative for common SCA repeat expansions. All deletions detected by MLPA were confirmed by SNP-array. One of the ITPRI deletions preserved exons 1 and 2 in the $5^{\prime}$ prime UTR of the ITPRI gene. All SCA15 patients $(n=10)$ presented with slowly progressive cerebellar ataxia and vermal cerebellar atrophy, while clinical and electrophysiological signs of extra-cerebellar affection were mild and more variable.

Conclusions: SCA15 is the most common non-trinucleotide repeat SCA in Central Europe. Screening for ITPRI deletions should be considered in patients with slowly progressive SCA, vermal cerebellar atrophy and prominent tremor after excluding common SCA repeat expansions. Promotor and exon 2 of ITPRI may be preserved from the deletion in some cases of SCA15.

Keywords: $\quad$ spinocerebellar ataxias; genetics, prevalence studies; cerebellum; movement disorders 


\section{Introduction}

Spinocerebellar ataxias (SCAs) are a clinically and genetically heterogeneous group of autosomal dominant cerebellar ataxias with an overall prevalence of $3 / 100,000[1,2]$. Up to now, 28 SCA loci have been identified, whereby more than $60 \%$ of all SCAs are caused by CAG repeat expansions in the SCA1, SCA2, SCA3, SCA6 and SCA7 genes [1]. Patients with autosomal-dominant ataxia who are negative for these mutations present a diagnostic challenge as the remaining SCA mutations include very low frequency genes (e.g. SCA11[3] or SCA28[4]) and gene candidates that still warrant further confirmation (e.g. SCA20 [5] or SCA30 [6]). To guide cost- and time-efficient genetic screening, more information about frequency, phenotypic characteristics and optimal diagnostic strategies in recently identified SCA subtypes is highly warranted.

SCA15 was recently found to be caused by multi-exon deletions and, more rarely and still debated, by missense mutations in the ITPRl-gene (inositol 1,4,5-triphosphate receptor, type 1) $[7,8,9,10]$. The phenotype of SCA15 has been studied in only relatively few patients as only 9 SCA15 families have been identified worldwide [10, 11], and the frequency of SCA15 in the European population is still unknown. In addition, the most efficient diagnostic method remains to be settled as several different molecular-genetic techniques have been used to detect ITPRI deletions - in particular deletion-specific PCR [9], different DNA microarrays [7, 8] or multiplex ligation-dependent probe amplification (MLPA) [10]. We here determined the frequency and phenotypic spectrum of SCA15 by screening a large cohort of SCA families negative for common SCA repeat expansions for deletions in the ITPRI-gene by a customized MLPA assay.

\section{Material and Methods}

\section{Patient selection and assessment}


A consecutive series of 274 German families with autosomal dominant transmission of ataxia was recruited from ataxia clinics in Bochum, Bonn and Tübingen (= all SCAs). Out of this sample, we selected those index patients for SCA15 screening who were negative for repeat expansions causing SCA1, SCA2, SCA3, SCA6, SCA7, SCA8, SCA10, SCA12, SCA17, and DRPLA and for mutations causing SCA11, SCA14, and SCA27, yielding a cohort of 60 index patients (= unexplained SCAs). Four of these patients were excluded from the study due to low quantity and/or insufficient quality of the respective DNA samples. Mean age of onset of the remaining index patients $(\mathrm{n}=56)$ was $43.8+/-17.4$ years (range: $3-71) .50 \%(28 / 56)$ of the index patients presented with pure cerebellar ataxia and 50\% with non-cerebellar signs like gaze palsy, epilepsy, spasticity, dystonia, Parkinsonism or peripheral neuropathy.

All index patients and, if available, further affected family members were assessed (i) by a clinical examination through a movement disorder specialist (M.S., L.S.) to identify cerebellar and non-cerebellar features, (ii) by the Scale for the Assessment and Rating of Ataxia (SARA) [12] to determine severity and progression of ataxia, (iii) by magnetic resonance imaging (MRI) and (iv) by electrophysiological studies (including nerve conduction studies, motor evoked potentials, and sensory evoked potentials).

\section{Molecular genetic analyses}

In a first step, multiplex ligation-dependent probe amplification (MLPA) was used to screen for ITPR1 deletions. We designed a MLPA assay targeting the gene's promoter as well as exons $2,8,18,41$ and 54 and intron 4 with one probe each (=7 probes total). These targets were selected to cover especially 5' portions of the ITPRI gene as all deletions reported previously included at least exons 1 to 10 [10, 11]. Six probes targeting different chromosomes were included for reference (ITPRI MLPA probe sequences, reference MLPA probes for other genomic regions, and size distribution of MLPA probes in the ITPRI assay are given in supplementary table 1). Pertinent oligonucleotides were obtained from MWG- 
Biotech (Germany) and reagents were taken from the EK1 kit offered by MRC-Holland (The Netherlands); they were applied according to the manufacturers' instructions. Analysis of MLPA data was carried out in analogy to previously described MLPA analyses [13].

In a second step, high-density SNP array was used for validation purposes and determination of the size of the deletion in all index cases for which MLPA suggested the presence of a heterozygous deletion. Samples were evaluated by an Affymetrix 6.0 SNP array platform using copy number variation (CNV) and analyzed with the Affymetrix CN4 algorithms within GTC v3. The predicted copy number as well as the start and end of the each CNV segment were determined using the Hidden Markov Model (HMM) incorporated in the software package using the Viterbi algorithm. For the ITPRI-SUMF1 locus approx. 380 markers were looked up for genomic imbalances as indicated by a reduction or amplification of hybridization signal (CNV) or excess of homozygosity. For the mathematical computation of the CNV sizes a sliding window method is used.

To investigate the potential effect of the $5^{\prime}$ end on expression of the ITPRI gene in family F34, a quantitative real time PCR (qPCR) was designed for amplicons in exon 3 (including the start codon) and exon 6 of the ITPRI gene. Primers are given in supplementary table 1. PCR amplification was performed in triplicates using a LightCycler480 system (Roche, Mannheim, Germany) with $10 \mu \mathrm{L}$ PCR volumes in the 384-well block format using a standard qPCR protocol $\left(15 \mathrm{~min} .95^{\circ} \mathrm{C}, 45\right.$ cycles with $20 \mathrm{sec} .95^{\circ} \mathrm{C}, 40 \mathrm{sec} .55^{\circ} \mathrm{C}$, and $20 \mathrm{sec}$. at $72^{\circ} \mathrm{C}$, followed by a melting curve from $40^{\circ} \mathrm{C}$ to $85^{\circ} \mathrm{C}$ ) with hotstart SYBRgreen chemistry (Roche, Mannheim, Germany). We established comparable amplification efficiencies for ITPRIamplicons and reference amplicons within the $B C M A, S D C 4$, and $B 2 M G$ genes using the relQuant analysis tool of the LightCycler software version 1.5. A reduction in qPCR signal by $<70 \%$ was defined as indicating a deletion.

\section{Results}




\section{Genetic screening}

MLPA suggested partial ITPRI deletions in 5/56 index patients, but provided no evidence for multiplications (Figure 1; for detailed individual quantitative MLPA data, see supplementary table 2). Pedigrees of SCA15 families are provided in supplementary figure 1. In family F34 the deletion did not affect the 5' end of the ITPRI gene: MLPA in all 3 affected family members revealed that this ITPRI-deletion preserved the promoter region and exon 2 of ITPRI (figure 1 and supplementary table 2).

In 4 of 5 index patients, heterozygous genomic ITPRI deletions were confirmed by copy number analysis by SNP array. In these patients 176 to 383 markers were included in the deletion regions. Deletions - as measured by $\mathrm{CNV}$ - spanned approximately $183 \mathrm{~kb}$ to $423 \mathrm{~kb}$ (for details see table 1 and figure 2). The size of one deletion (F06-III-8) could not be determined by SNP-array analysis as compromised DNA quality did not allow accurate measurements (technical failure). Deletions in F39, F48 and F49 affected partly both the ITPRI- and the SUMF1-gene, without including the 3' prime of the ITPRI-gene (figure 2). In family F34, CNV array analysis did partially differ from MLPA results by predicting the border of the ITPR1-deletion about 10kb upstream of that defined by the MLPA markers (figure 2).

Since MLPA data in all affected members of family F34 consistently suggested that the deletion starts between exon 2 and intron 4 we designed a qPCR with primers covering the ATG triplet in exon 3 of ITPRI. In all three affected members of family F34 qPCR indicated the start codon to be deleted (qPCR fragment localization are shown in figure 2). The ITPRI deletions co-segregated with the disease in kindreds F34 and F48 (figure 1). In F06 and F49 no further family members were available for genetic testing. In F39, the father of the index patient had deceased and no DNA was available, but pertinent clinical records confirmed affection by cerebellar ataxia. 


\section{Phenotype and disease progression}

Detailed clinical, electrophysiological and imaging characterisation was available for ten patients and is summarized in Tables 2 and 3. Exemplary videos are available as supplementary material. In these ten patients, SCA15 presented clinically with a mid-life onset of 44.6 years (range 30-67 years) and a rather uniform phenotype of slowly progressive cerebellar ataxia ( 1.2 SARA points/year, range 0.7-1.7; Tab. 2). A walker or wheelchair was needed around 15-17 years after disease onset. In 9/10 individuals the initial symptom was gait disturbance. Interestingly, 3 subjects (F34-IV-3, F34-IV-4, F48-III-1) considered themselves to be asymptomatic despite unequivocal signs of cerebellar ataxia and cerebellar atrophy on MRI (figure 3, c-f). Two of them had been clinically diagnosed for more than 5 years. This fact again highlights the subtle and slow progression of the disease.

As a characteristic feature, action and postural tremor of the hands and partly of the head were found in $7 / 10$ patients. It aggravated the intention tremor which was consistently observed in all subjects. Subjects perceived tremor as one of the most compromising impairments for activities of daily living. In 3/7 subjects action and postural tremor evolved rather late in the disease course (14-17 years after ataxia onset; Table 2). Other extracerebellar features included clinical or electrophysiological signs of pyramidal tract affection (4/10 patients), electrophysiological evidence of dorsal column pathology (4/10 patients) and upward gaze palsy (1/10 patients) (Tables 2 and 3 ). Two patients showed psychiatric symptoms already before the onset of ataxia (paranoid-hallucinatory psychosis in F34-IV-3; adjustment disorder in F39-III-4), one elderly patient revealed mild cognitive impairment (F49-III-3) presumably due to vascular encephalopathy. None of the patients showed facial myokymias or buccolingual dyskinesias which have recently been reported in some SCA15 patients [11]. In line with previous findings [14], MRI demonstrated a rather uniform pattern of cerebellar atrophy affecting mainly the vermis (in particular superior and mid-vermal regions), with only minor hemispheric involvement and sparing of brainstem and cerebral structures (figure 3). 
Atrophy seemed to progress only slowly within 4 and 5 years of follow-up, respectively (figure 3, g-j, m-p). However, no data for quantitative volumetric analysis were available.

\section{Discussion}

In our series SCA15 is relatively frequent, accounting for $8.9 \%(5 / 56)$ of unexplained SCAs and $1.8 \%(5 / 274)$ of all SCAs. This finding exceeds a recent, also MLPA-based estimate of 2.7\% ITPRI deletions in Australian SCA cases negative for repeat expansions [10]. It clearly exceeds the reported prevalence of other "new" SCA subtypes like SCA14 [15], SCA11 [16], SCA27 [17] or SCA28 [4]. Thus, SCA15 seems to present the fifth most common SCA subtype after SCA1, 2, 3 and 6 and is even more frequent than SCA7, 8 and 17 in the German population.

Our customized MLPA assay allowed for the consistent measurement of seven target regions distributed over the ITPRl-gene, demonstrating that each family in our series had a unique deletion. Moreover, it revealed that SCA15 can also be caused by heterozygous deletions that spare the first 2 non-coding exons, while previous studies always demonstrated inclusion of ITPR1-exon 1 in SCA15 deletions [8, 10]. Whereas MLPA (and qPCR) are locus specific tools for measuring gene dosage, SNP array copy number analysis has to rely on serial data points in order to size variations. This might explain why the deletion genotyped in all three SCA15 patients of family F34 resulted in consistent results for MLPA (and qPCR), but not for CNV arrays: although the telomeric border was identical for all patients, it did not combine with our MLPA data, and the centromeric border varied for almost 15.000 bases. Moreover, for the mathematical computation of deletion sizes in the CNV array a sliding window method was used, which frequently leads to over-estimation of the deletion size (in our case the questionable region is covered by only 9 SNPs). Correspondingly, since MLPA data consistently demonstrated the promoter region and exon 2 of ITPRI to be preserved in all affected members, we believe that the $\mathrm{CNV}$ array method indicated too large genomic 
deletion regions. To address the effect of the unusual preservation of the 5 ' end we designed a qPCR system, which demonstrated inclusion of the ITPRI start codon in exon 3 by the deletion. Thus, no proper protein translation can take place and this deletion resembles all other deletions by entailing IPTRI haploinsufficiency.

Variability of deletion size as found in our and other studies would argue for high resolution deletion detection systems that completely interrogate all ITPRI-exons. This fact also indicates that our screening by MLPA might even underestimate the true SCA15 prevalence, as this approach may miss small deletions of exons not covered by the MLPA probe-sets used in this study. Moreover, this approach cannot reliably detect point mutations in the ITPRI gene. So far, a single amino acid change of unknown significance is reported in one patient (c.8581C > T, p.P1059L; [8]). The frequency of ITPR1 point mutations and small deletions in SCA families, however, seems to be very low, as they have not been found in 38 SCA families that were negative for large ITPRI deletions and common SCA mutations [18]. Although our study recommends MLPA as a cost and time-efficient screening tool for SCA15, for individual tests rather than testing of a cohort, a DNA microarray approach might still be most efficient.

In a comprehensive phenotypic characterization of our series of SCA15 patients we confirmed findings of earlier reports with smaller patient numbers [11, 14, 19] and identified several characteristic features that might be helpful for considering ITPRl-deletion screening in unexplained SCA patients. Disease progression in our SCA15 cohort was relatively slow (1.2 SARA points/year) compared to SCA2 (1.4 SARA points/year), SCA3 (1.6 SARA points/year) or SCA1 ( 2.2 SARA points/year), yet somewhat faster than in SCA6 (non-linear progression: first year: 0.35 SARA points/year, second year: 1.44 SARA points/year) [20]. This finding, however, needs to be confirmed in prospective studies with iterative SARA evaluations as retrospective estimation of disease onset in such a slowly progressive disease 
course is difficult. Disabling action and postural tremor, found in $70 \%$ of our patients, seems to be characteristic of (albeit not specific to) SCA15 [19]. It may present as the initial symptom (see patient F48-III-7 and [14]), or develop more than a decade after onset of ataxia. Intriguingly, all patients (100\%) demonstrated cerebellar atrophy affecting mainly the superior and mid-vermal regions, with only minor hemispheric involvement and sparing of the brainstem and cerebral structures. This atrophy pattern may occur even before subjectively noticed ataxia (patients IV-3 and IV-4 of family F34).

Contrary to earlier perspectives which considered SCA15 to be a pure cerebellar ataxia [21], extra-cerebellar features such as pyramidal tract affection, dorsal column pathology or gaze paresis might be associated with SCA15 as well (as they are in many other SCAs [1]), yet present in a more variable fashion.

In conclusion, we show that SCA15 presents the most common non-trinucleotide repeat SCA in Central Europe. MLPA seems to serve as a robust and cost-effective screening tool for ITPRI deletions. Screening for ITPRI deletions should be particularly performed in patients with unexplained SCA presenting with slowly progressive ataxia, prominent tremor and pronounced vermal atrophy of the cerebellum.

\section{Acknowledgements}

We are grateful to the family members for their participation. This work was funded by the European Union (to the EUROSCA consortium; LSHM-CT-2004-503304) and the Stiftung für Pathobiochemie und Molekulare Diagnostik (to C.B.). MS was supported by a grant from the Volkswagen Stiftung (Az. II/85158). 


\section{References}

1 Schols L, Bauer P, Schmidt T, et al. Autosomal dominant cerebellar ataxias: clinical features, genetics, and pathogenesis. Lancet Neurol 2004;3(5):291-304.

2 van de Warrenburg BP, Sinke RJ, Verschuuren-Bemelmans CC, et al. Spinocerebellar ataxias in the Netherlands: prevalence and age at onset variance analysis. Neurology 2002;58(5):702-8.

3 Bauer P, Stevanin G, Beetz C, et al. Spinocerebellar ataxia type 11 (SCA11) is an uncommon cause of dominant ataxia among French and German kindreds. J Neurol Neurosurg Psychiatry 2010;81:1229-32.

4 Edener U, Wollner J, Hehr U, et al. Early onset and slow progression of SCA28, a rare dominant ataxia in a large four-generation family with a novel AFG3L2 mutation. Eur J Hum Genet 2010;18(8):965-8.

$5 \quad$ Knight MA, Hernandez D, Diede SJ, et al. A duplication at chromosome 11q12.2$11 \mathrm{q} 12.3$ is associated with spinocerebellar ataxia type 20. Hum Mol Genet 2008;17(24):3847-53.

6 Storey E, Bahlo M, Fahey M, et al. A new dominantly inherited pure cerebellar ataxia, SCA 30. J Neurol Neurosurg Psychiatry 2009;80(4):408-11.

7 van de Leemput J, Chandran J, Knight MA, et al. Deletion at ITPR1 underlies ataxia in mice and spinocerebellar ataxia 15 in humans. PLoS Genet 2007;3(6):e108.

8 Hara K, Shiga A, Nozaki H, et al. Total deletion and a missense mutation of ITPR1 in Japanese SCA15 families. Neurology 2008;71(8):547-51.

9 Iwaki A, Kawano Y, Miura S, et al. Heterozygous deletion of ITPR1, but not SUMF1, in spinocerebellar ataxia type 16. J Med Genet 2008;45(1):32-5.

10 Ganesamoorthy D, Bruno DL, Schoumans J, et al. Development of a Multiplex Ligation-Dependent Probe Amplification Assay for Diagnosis and Estimation of the Frequency of Spinocerebellar Ataxia Type 15. Clin Chem 2009;55(7):1415-8.

11 Di Gregorio E, Orsi L, Godani M, et al. Two Italian families with ITPR1 gene deletion presenting a broader phenotype of SCA15. Cerebellum 2010;9(1):115-23.

12 Schmitz-Hubsch T, du Montcel ST, Baliko L, et al. Scale for the assessment and rating of ataxia: development of a new clinical scale. Neurology 2006;66(11):1717-20.

13 Schule R, Brandt E, Karle KN, et al. Analysis of CYP7B1 in non-consanguineous cases of hereditary spastic paraplegia. Neurogenetics 2009;10(2):97-104.

14 Gardner RJ, Knight MA, Hara K, et al. Spinocerebellar ataxia type 15. Cerebellum 2005;4(1):47-50.

15 Klebe S, Durr A, Rentschler A, et al. New mutations in protein kinase Cgamma associated with spinocerebellar ataxia type 14. Ann Neurol 2005;58(5):720-9.

16 Bauer P, Stevanin G, Beetz C, et al. Spinocerebellar ataxia type 11 (SCA11) is an uncommon cause of dominant ataxia among French and German kindreds. J Neurol Neurosurg Psychiatry 2010.

17 Brusse E, de Koning I, Maat-Kievit A, et al. Spinocerebellar ataxia associated with a mutation in the fibroblast growth factor 14 gene (SCA27): A new phenotype. Mov Disord 2006;21(3):396-401.

18 van de Leemput J, Wavrant-De Vrieze F, Rafferty I, et al. Sequencing analysis of the ITPR1 gene in a pure autosomal dominant spinocerebellar ataxia series. Mov Disord 2010;25(6):763-5.

19 Hara K, Fukushima T, Suzuki T, et al. Japanese SCA families with an unusual phenotype linked to a locus overlapping with SCA15 locus. Neurology 2004;62(4):648-51.

20 Jacobi H, Bauer P, Giunti P, et al. The natural history of spinocerebellar ataxia type 1, 2, 3 and 6: a 2-year follow-up study. submitted. 
21 Storey E, Gardner RJ, Knight MA, et al. A new autosomal dominant pure cerebellar ataxia. Neurology 2001;57(10):1913-5.

\section{Licence for publication statement:}

The Corresponding Author has the right to grant on behalf of all authors and does grant on behalf of all authors, an exclusive on a worldwide basis to the BMJ Publishing Group Ltd and its Licensees to permit this article (if accepted) to be published in Journal of Medical Genetics and any other BMJPGL products to exploit all subsidiary rights, as set out in the licence. 


\section{Table 1: SNP array analysis in SCA15 patients}

Detailed deletion sizes and affected SNPs are given according to the Hidden Markov Model (HMM). Patient F06-III-8 was not included because compromised DNA quality did not allow accurate SNP-array analyses (technical failure).

\begin{tabular}{|c|c|c|c|c|c|c|}
\hline ID & Size & Markers & Start & End & Start / Marker & End Marker \\
\hline F34 III-2 & $423 \mathrm{~kb}$ & 383 & 4521773 & 4944763 & $\begin{array}{l}5^{`} \text { UTR ITPR 1 } \\
\text { SNP_A-8328224 }\end{array}$ & $\begin{array}{l}3^{`} \text { UTR ITPR1 } \\
\text { SNP_A-8319160 }\end{array}$ \\
\hline F34 IV-4 & $407 \mathrm{~kb}$ & 377 & 4521773 & 4928818 & \begin{tabular}{|l|} 
5‘UTR ITPR1 \\
SNP_A-8328224
\end{tabular} & \begin{tabular}{|l|} 
3`UTR ITPR1 \\
SNP_A-2196964
\end{tabular} \\
\hline F34 IV-3 & $408 \mathrm{~kb}$ & 379 & 4521773 & 4929877 & \begin{tabular}{|l} 
5‘UTR ITPR1 \\
SNP_A-8328224
\end{tabular} & $\begin{array}{l}\text { 3‘ UTR ITPR1 } \\
\text { CN_1044140 }\end{array}$ \\
\hline F39 III-4 & $206 \mathrm{~kb}$ & 196 & 4477165 & 4683436 & $\begin{array}{l}\text { Intron 3 SUMF1 } \\
\text { SNP_A-1940542 }\end{array}$ & $\begin{array}{l}\text { Intron 6 ITPR1 } \\
\text { SNP_A-8427137 }\end{array}$ \\
\hline F48 III-7 & $219 \mathrm{~kb}$ & 212 & 4493662 & 4712980 & $\begin{array}{l}\text { Intron 2 SUMF1 } \\
\text { SNP_A-2122078 }\end{array}$ & $\begin{array}{l}\text { Intron 20 ITPR1 } \\
\text { CN_1033009 }\end{array}$ \\
\hline F49 III-3 & $183 \mathrm{~kb}$ & 176 & 4484080 & 4667436 & $\begin{array}{l}\text { Intron 3 SUMF1 } \\
\text { SNP_A-1898571 }\end{array}$ & $\begin{array}{l}\text { Intron 4 ITPR1 } \\
\text { SNP_A-1805189 }\end{array}$ \\
\hline
\end{tabular}


Table 2: Clinical findings in SCA15 patients.

\begin{tabular}{|c|c|c|c|c|c|c|c|c|c|c|c|c|c|c|c|c|}
\hline \multirow{2}{*}{$\begin{array}{l}\text { Fami } \\
\text { ly }\end{array}$} & \multirow{2}{*}{$\begin{array}{l}\text { pedigree } \\
\text { number }\end{array}$} & \multirow{2}{*}{$\begin{array}{l}\text { Age at } \\
\text { last } \\
\text { exami } \\
\text { nation }\end{array}$} & \multicolumn{2}{|c|}{ age of onset } & \multirow{2}{*}{$\begin{array}{l}\text { disease } \\
\text { progressio } \\
\mathrm{n} \\
\text { (SARA } \\
\text { Score } \\
\text { /disease } \\
\text { duration) }\end{array}$} & \multirow{2}{*}{$\begin{array}{l}\text { initial } \\
\text { features }\end{array}$} & \multirow{2}{*}{$\begin{array}{l}\text { gait ataxia } \\
\text { (SARA item } \\
\text { gait) }\end{array}$} & \multirow{2}{*}{$\begin{array}{l}\text { limb } \\
\text { dysmetria }\end{array}$} & \multirow[t]{2}{*}{ Dysarthria } & \multirow{2}{*}{$\begin{array}{l}\text { dyspha } \\
\text { gia }\end{array}$} & \multicolumn{2}{|c|}{ eye movements } & \multirow{2}{*}{$\begin{array}{l}\text { pyramidal } \\
\text { features }\end{array}$} & \multirow{2}{*}{$\begin{array}{l}\text { postural/ } \\
\text { action } \\
\text { tremor }\end{array}$} & \multirow{2}{*}{$\begin{array}{l}\text { intention } \\
\text { tremor }\end{array}$} & \multirow[t]{2}{*}{ other features } \\
\hline & & & $\begin{array}{l}\text { Gait } \\
\text { distur } \\
\text { bance }\end{array}$ & $\begin{array}{l}\text { Postural } \\
\text { tremor }\end{array}$ & & & & & & & Nystagmus & $\begin{array}{l}\text { saccade } \\
\mathrm{s}\end{array}$ & & & & \\
\hline \multirow{3}{*}{ mે } & III-2 & 80 & 60 & 74 & $24 / 20=1.2$ & $\begin{array}{l}\text { gait } \\
\text { disturbanc } \\
\mathrm{e}\end{array}$ & $\begin{array}{l}7 \\
\text { (wheelchair } \\
\text { with } 75 \text { yrs } \\
\text { of age) }\end{array}$ & $\begin{array}{l}+(\mathrm{UE} \text { and } \\
\mathrm{LE})\end{array}$ & ++ & + & $\begin{array}{l}\text { Horizontal + } \\
\text { vertical } \\
\text { gaze-evoked }\end{array}$ & $\begin{array}{l}\text { Hyperm } \\
\text { etric }\end{array}$ & $\mathrm{n}$ & $\begin{array}{l}++ \\
\text { (UE\&LE) }\end{array}$ & $\begin{array}{l}+++(\text { UE \& } \\
\text { LE) }\end{array}$ & $\mathrm{n}$ \\
\hline & IV-3 & 46 & 41 & n.a. & $6 / 5=1.2$ & dizziness & 2 & $\begin{array}{l} \pm \text { (only } \\
\text { UE) }\end{array}$ & $\mathrm{n}$ & $\mathrm{n}$ & $\begin{array}{l}\text { transient } \\
\text { horizonal } \\
\text { gaze-evoked }\end{array}$ & $\begin{array}{l}\text { hypo- } \\
\text { and } \\
\text { hyperm } \\
\text { etric }\end{array}$ & $\mathrm{n}$ & $+(\mathrm{UE})$ & $\begin{array}{l}+(\mathrm{UE} \\
\& \mathrm{LE})\end{array}$ & $\begin{array}{l}\text { hyporeflexia } \\
\text { LE; transient } \\
\text { paranoid- } \\
\text { hallucinatory } \\
\text { psychosis } \\
\text { (22yrs of age) }\end{array}$ \\
\hline & IV-4 & 51 & 46 & n.a. & $5.5 / 5=1.1$ & $\begin{array}{l}\text { gait } \\
\text { disturbanc } \\
\text { e } \\
\text { (subjectiv } \\
\text { ely still } \\
\text { not } \\
\text { noticed) }\end{array}$ & 2 & $\begin{array}{l} \pm(\text { only } \\
\mathrm{LE})\end{array}$ & $\mathrm{n}$ & $\mathrm{n}$ & $\mathrm{n}$ & $\begin{array}{l}\text { hypo- } \\
\text { and } \\
\text { hyperm } \\
\text { etric }\end{array}$ & $\mathrm{n}$ & $\mathrm{n}$ & $+(\mathrm{LE})$ & $\mathrm{n}$ \\
\hline \multirow{2}{*}{ ले } & II-3 & 62 & 45 & 50 & ,slow" & $\begin{array}{l}\text { gait } \\
\text { disturbanc } \\
\mathrm{e}\end{array}$ & $\begin{array}{l}\text { n.a. } \\
\text { (walking } \\
\text { frame with } \\
62 \text { yrs of } \\
\text { age) }\end{array}$ & $\begin{array}{l}+ \\
(\mathrm{UE}+\mathrm{LE})\end{array}$ & + & + & $\begin{array}{l}\text { horizonal } \\
\text { gaze-evoked }\end{array}$ & $\begin{array}{l}\text { Hypom } \\
\text { etric }\end{array}$ & $\begin{array}{l}+( \\
\text { extensor } \\
\text { plantar } \\
\text { response, } \\
\text { but not } \\
\text { spasticity) }\end{array}$ & $+(\mathrm{UE})$ & $+(\mathrm{LE})$ & $\mathrm{n}$ \\
\hline & III-4 & 50 & 35 & 49 & $\begin{array}{l}16.5 / 15=1 \\
.1\end{array}$ & $\begin{array}{l}\text { gait } \\
\text { disturbanc } \\
\mathrm{e}\end{array}$ & 3 & $\begin{array}{l}+ \\
(\mathrm{UE}+\mathrm{LE})\end{array}$ & $\mathrm{n}$ & $\mathrm{n}$ & $\mathrm{n}$ & $\mathrm{n}$ & $\bar{n}$ & $\begin{array}{l}\text { (head, } \\
\text { UE, LE) }\end{array}$ & + & $\begin{array}{l}\text { upward gaze } \\
\text { palsy; } \\
\text { adjustment } \\
\text { disorder }\end{array}$ \\
\hline$\stackrel{\infty}{\mathfrak{I}}$ & II-3 & 69 & 50 & 67 & $\begin{array}{l}21.5 / 19= \\
1.1\end{array}$ & $\begin{array}{l}\text { gait } \\
\text { disturbanc } \\
\mathrm{e}\end{array}$ & $\begin{array}{l}4 \text { (partial use } \\
\text { of crutches } \\
\text { with } 64 \text { yrs } \\
\text { of age) }\end{array}$ & $\begin{array}{l}+ \\
(\mathrm{UE}+\mathrm{LE})\end{array}$ & ++ & + & $\begin{array}{l}\text { Horizontal + } \\
\text { vertical } \\
\text { gaze-evoked }\end{array}$ & $\begin{array}{l}\text { hypo- } \\
\text { and } \\
\text { hyperm } \\
\text { etric }\end{array}$ & $\mathrm{n}$ & $\begin{array}{l}+(\mathrm{UE} ; \\
\text { trunk) }\end{array}$ & $+(\mathrm{UE})$ & $\mathrm{n}$ \\
\hline
\end{tabular}




\begin{tabular}{|c|c|c|c|c|c|c|c|c|c|c|c|c|c|c|c|c|}
\hline & III-1 & 33 & 33 & n.a. & $\begin{array}{l}\# \\
\text { (currently: } \\
10.5 \\
\text { SARA } \\
\text { points) }\end{array}$ & $\begin{array}{l}\text { gait } \\
\text { disturbanc } \\
\mathrm{e} \\
\text { (subjectiv } \\
\text { ely still } \\
\text { not } \\
\text { noticed) }\end{array}$ & 2 & $\begin{array}{l} \pm \text { (only } \\
\text { UE) }\end{array}$ & $\mathrm{n}$ & $\mathrm{n}$ & $\begin{array}{l}\text { all directions } \\
\text { gaze-evoked }\end{array}$ & $\begin{array}{l}\text { hypo- } \\
\text { and } \\
\text { hyperm } \\
\text { etric }\end{array}$ & $\begin{array}{l}+ \\
\text { (spasticity } \\
\text { and } \\
\text { hyperreflex } \\
\text { ia UE) }\end{array}$ & $\mathrm{n}$ & $+(\mathrm{UE} \& \mathrm{LE})$ & $\mathrm{n}$ \\
\hline & III-7 & 41 & 31 & 31 & $\begin{array}{l}11.5 / 10=1 \\
.2\end{array}$ & $\begin{array}{l}\text { gait } \\
\text { disturbanc } \\
\mathrm{e}\end{array}$ & 2 & $\begin{array}{l}+ \\
\text { (UE\&LE) }\end{array}$ & + & + & $\begin{array}{l}\text { horizontal } \\
\text { gaze-evoked }\end{array}$ & $\begin{array}{l}\text { hypo- } \\
\text { and } \\
\text { hyperm } \\
\text { etric }\end{array}$ & $\mathrm{n}$ & $\begin{array}{l}++ \text { (UE; } \\
\text { LE, head, } \\
\text { trunk) }\end{array}$ & $+($ UE\&LE) & $\mathrm{n}$ \\
\hline से & III-3 & 73 & 67 & 69 & $10 / 6=1.7$ & $\begin{array}{l}\text { gait } \\
\text { disturbanc } \\
\mathrm{e}\end{array}$ & 3 & $\begin{array}{l}+ \\
\text { (UE\&LE) }\end{array}$ & + & $\mathrm{n}$ & $\begin{array}{l}\text { horizontal } \\
\text { gaze evoked }\end{array}$ & $\begin{array}{l}\text { hypo- } \\
\text { and } \\
\text { hyperm } \\
\text { etric }\end{array}$ & $\mathrm{n}$ & $+(\mathrm{UE})$ & $\begin{array}{l}+ \\
\text { (UE, LE) }\end{array}$ & $\begin{array}{l}\text { vascular } \\
\text { encephalopath } \\
\text { y; mild } \\
\text { cognitive } \\
\text { impairment } \\
\text { (Mini Mental } \\
\text { State 24/30 } \\
\text { pts) }\end{array}$ \\
\hline : & III-8 & 40 & 30 & n.a. & $7 / 10=0.7$ & $\begin{array}{l}\text { gait } \\
\text { disturbanc } \\
\mathrm{e}\end{array}$ & 2 & $\begin{array}{l}+ \\
\text { (UE\&LE) }\end{array}$ & $\mathrm{n}$ & $\mathrm{n}$ & $\begin{array}{l}\text { Horizontal + } \\
\text { vertical } \\
\text { gaze-evoked }\end{array}$ & $\begin{array}{l}\text { hypo- } \\
\text { and } \\
\text { hyperm } \\
\text { etric }\end{array}$ & $\mathrm{n}$ & $\mathrm{n}$ & $\begin{array}{l}+ \\
\text { (UE, LE) }\end{array}$ & $\mathrm{n}$ \\
\hline
\end{tabular}

n=none; \pm questionable; n.a.= not available; $+=$ mildly abnormal/affected; ++= moderately abnormal/affected; +++= severely abnormal/affected;

$\mathrm{UE}=$ upper extremity; LE=lower extremity. *SARA, Scale for the Assessment and Rating of Ataxia, maximum score 40, minimum score 0. Disease progression is calculated by SARA score last examination/ disease duration. ** SARA item gait, maximum score 8 , minimum score 0 . \# Disease duration was not determinable in F48 III-1 as she was subjectively still unaffected and no previous assessment had been performed before. Ages and durations of symptoms in years. 
Table 3: MRI and electrophysiology data

\begin{tabular}{|c|c|c|c|c|c|c|}
\hline $\begin{array}{l}\text { fam } \\
\text { ily }\end{array}$ & $\begin{array}{l}\text { pedigree } \\
\text { number }\end{array}$ & MRI & MEP & SEP & NCS & Other \\
\hline \multirow{3}{*}{ m } & III-2 & $\begin{array}{l}\text { cerebellar atrophy } \\
\text { (vermis> hemispheres) }\end{array}$ & $\mathrm{n}$ & not evoked & $\mathrm{n}$ & $\mathrm{n}$ \\
\hline & IV-3 & $\begin{array}{l}\text { cerebellar atrophy } \\
\text { (vermis> hemispheres) } \\
\text { (CCT) }\end{array}$ & $\mathrm{n}$ & not evoked & $\mathrm{n}$ & $\mathrm{n}$. \\
\hline & IV-4 & $\begin{array}{l}\text { cerebellar atrophy } \\
\text { (vermis> hemispheres) }\end{array}$ & $\mathrm{n}$ & $\mathrm{n}$ & $\mathrm{n}$ & $\mathrm{n}$ \\
\hline \multirow[b]{2}{*}{ ले } & II-3 & $\begin{array}{l}\text { cerebellar atrophy } \\
\text { (vermis> hemispheres) }\end{array}$ & n.a. & n.a. & n.a. & $\mathrm{n}$ \\
\hline & III-4 & $\begin{array}{l}\text { cerebellar atrophy } \\
\text { (vermis> hemispheres) }\end{array}$ & $\begin{array}{l}\text { legs: not } \\
\text { evoked; } \\
\text { arms: } \\
\text { normal }\end{array}$ & $\mathrm{n}$ & $\mathrm{n}$ & $\begin{array}{l}\text { normal } \\
\text { electronysta } \\
\text { gmography }\end{array}$ \\
\hline \multirow{3}{*}{ 悉 } & II-3 & $\begin{array}{l}\text { cerebellar atrophy } \\
\text { (vermis> hemispheres) }\end{array}$ & $\begin{array}{l}\text { legs: not } \\
\text { evoked; } \\
\text { arms: } \\
\text { normal }\end{array}$ & $\begin{array}{l}\text { prolonged } \\
\text { latency } \\
\text { bilateral }\end{array}$ & $\mathrm{n}$ & $\begin{array}{l}\text { normal } \\
\text { cognitive } \\
\text { state } \\
\text { (MMSE } \\
29 / 30)\end{array}$ \\
\hline & III-1 & $\begin{array}{l}\text { cerebellar atrophy } \\
\text { (vermis }>\text { hemispheres) }\end{array}$ & n.a. & n.a. & n.a. & $\mathrm{n}$ \\
\hline & III-7 & $\begin{array}{l}\text { cerebellar atrophy } \\
\text { (vermis> hemispheres) }\end{array}$ & $\mathrm{n}$ & $\mathrm{n}$ & $\mathrm{n}$ & $\mathrm{n}$ \\
\hline$\underset{y}{\dot{y}}$ & III-3 & $\begin{array}{l}\text { cerebellar atrophy } \\
\text { (vermis> hemispheres) }\end{array}$ & $\mathrm{n}$ & $\begin{array}{l}\text { prolonged } \\
\text { latency } \\
\text { bilateral }\end{array}$ & $\begin{array}{l}\text { tibial } \\
\text { nerve: } \\
\text { reduced } \\
\text { amplitude; } \\
\text { sural } \\
\text { nerve: } \\
\text { normal }\end{array}$ & $\begin{array}{l}\text { normal VEP } \\
\text { and BAEP; } \\
\text { mild } \\
\text { cognitive } \\
\text { impairment } \\
\text { (MMSE } \\
\text { 24/30) }\end{array}$ \\
\hline$\sum_{\text {l }}^{0}$ & III-8 & $\begin{array}{l}\text { superior cerebellar } \\
\text { vermis atrophy }\end{array}$ & $\mathrm{n}$ & $\mathrm{n}$ & $\mathrm{n}$ & $\begin{array}{l}\text { normal } \\
\text { sympathetic } \\
\text { skin } \\
\text { response, } \\
\text { VEP and } \\
\text { BAEP }\end{array}$ \\
\hline
\end{tabular}




\section{Figure legends}

Figure 1: MLPA readouts for all SCA15 patients with heterozygous ITPR1 gene deletions.

(A) MLPA analysis allowed for the relative gene dosage measurements in seven localizations throughout the ITPRl-gene: hybridization probes have been placed in the promoter, in exon 2, intron 4 , exon 8 , exon 18, exon 41 and at the 3 prime end in exon 54 . Red bars visualize the minimal length of heterozygous ITPRI-deletions and demonstrate at least four different deletion sizes in our five families. (B) Exemplary MLPA data. Mean and SEM of healthy controls ( $\mathrm{n}=15)$ and SCA15 patients (3 (exon 54) to 9 (introns 4 and 8) observations; see also part (A)). Moreover, the relative peak area for patient F34-III-2 is shown in grey bars for the respective fragments. Values around 1.0 indicate presence of the normal two copies whereas values around 0.5 suggest a heterozygous deletion. (chr: chromosome; prom: promoter; ex: exon; in: intron; for calculation of relative signal value see Material and Methods section).

Figure 2: Copy number variation analysis for six SCA15 patients with heterozygous ITPR1 gene deletions.

Copy number plots of the relative gene dosage in the SCA15 region for three samples of family F34 (F34-III-2, F34-IV-3, F34-IV-4), F39-III-4, F48-III-7, and F49-III-3 are shown. F06-III-8 gave low quality results due to degraded DNA (not shown). A ruler with genomic coordinates and the relative position of the ITPRI and SUMF1 gene is shown. All individual deletion sizes (as determind by SNP array CNV) are shown as horizontal bars and labelled with the family code. Moreover, the exact position of all MLPA probes (promoter and exon 2 are very close to each other) and of the qPCR fragments is shown.

Figure 3: Brain imaging of SCA 15 patients. MRI and CT brain scans of 7 SCA15 patients demonstrating a highly uniform picture of prominent cerebellar atrophy affecting mainly the vermis (in particular the superior and mid-vermis), with only minor cerebellar hemispheric involvement and complete sparing of the brainstem and cerebral structures. MRI brain scans of patients F39 III-4 (g-j) and F48 III-7 (m-p) were assessed two times within 5 years and 4 years, respectively, indicating minor progression of vermal cerebellar atrophy.

Left columns: sagittal view; right columns transversal view; a,e: T2-weighted images; b, h, f, j, 1, n, p, r: T2 FLAIR; g, i, k, m, o, q: T1 flash sequences; c,d: CT scans. Patient IV-3 of 
family F34 could not be placed in a MRI head coil due to comorbid severe ankylosing spondylitis.

\section{Supplementary figure 1: Pedigree structure of SCA 15 families.}

Black symbols denote affected and open symbols unaffected individuals. Deceased family members are marked by a slash. * indicates age at last examination; + indicates age at death; dd indicates disease duration in years. Arrows mark individuals with DNA available for this study.

\section{Supplementary Videos}

\section{Legends to the videos:}

Video 1: Patient F34-III-2 at the age of 80 years displaying cerebellar oculomotor disturbance (in particular gaze evoked nystagmus) and dysarthria and the characteristic combination of combined postural, action and intention tremor, leading to severe impairments in everyday life.

Video 2: Patient F39-III-4 at the age of 50 years showing no signs of cerebellar oculomotor disturbance and no cerebellar dysarthria, but upward gaze palsy and the characteristic combination of combined head tremor and postural, action and intention tremor of the hands as well as cerebellar limb and gait ataxia. 


\section{A}
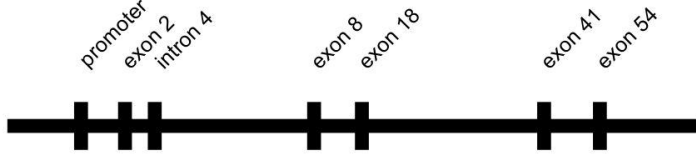

F06-III-8

F34-III-2

F34-IV-3

F34-IV-4

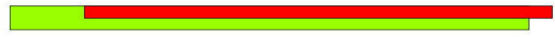

F39-II-3

F48-II-3

F48-III-1

F48-III-7

F49-III-3

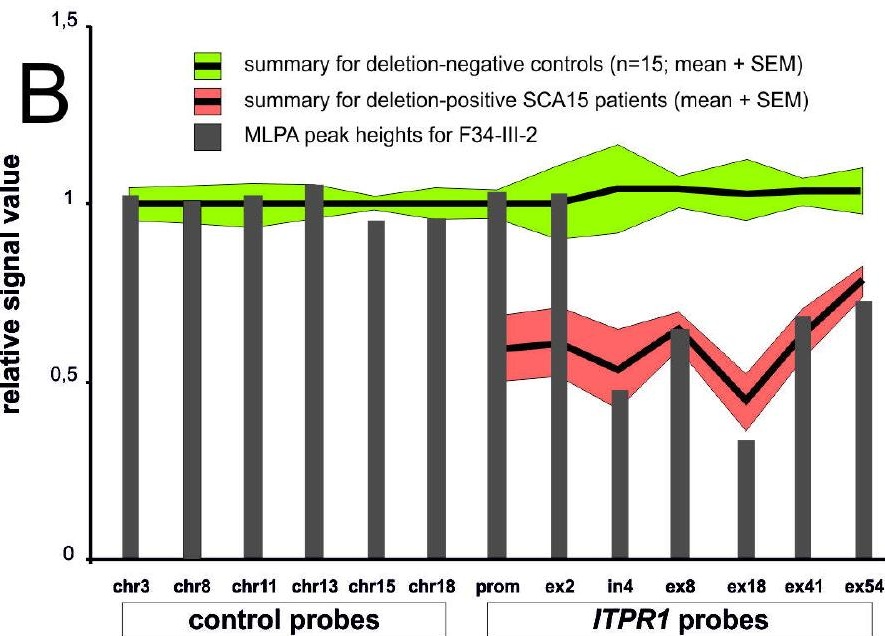


F34- II-2

F34- IV-3

F34- IV-4

F39-III-4

F48-III-7

F49 II-4

MLPA probes

qPCR fragments

\section{I} I I

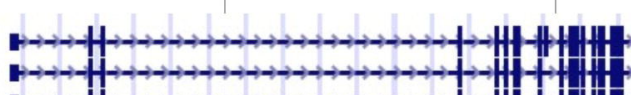

$\mathrm{F} \rightarrow \rightarrow-\rightarrow+1$ ITPR1 gene > 
F34 a

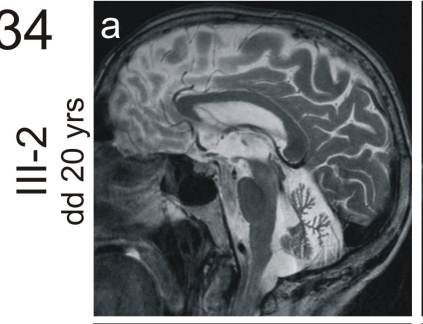

$m_{10}^{c} \sqrt{1}$ $\geq \frac{0}{2}$
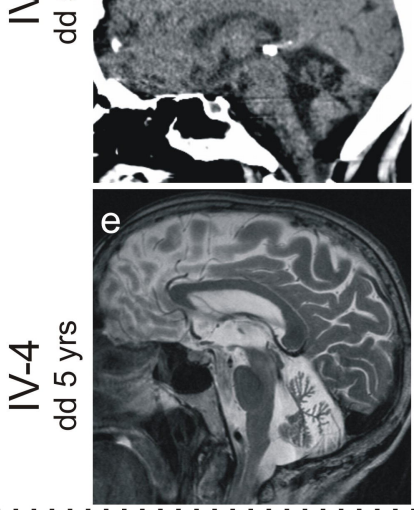

F39

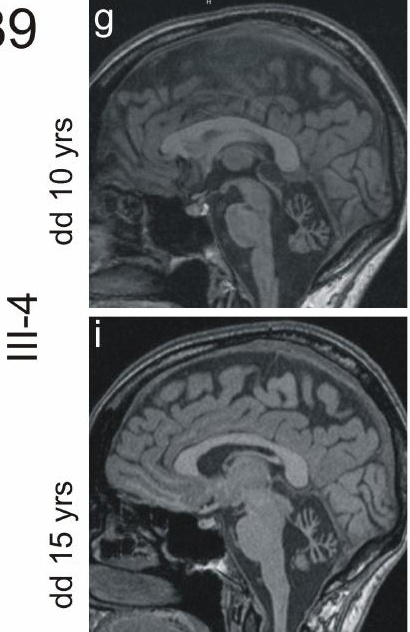

F48 k
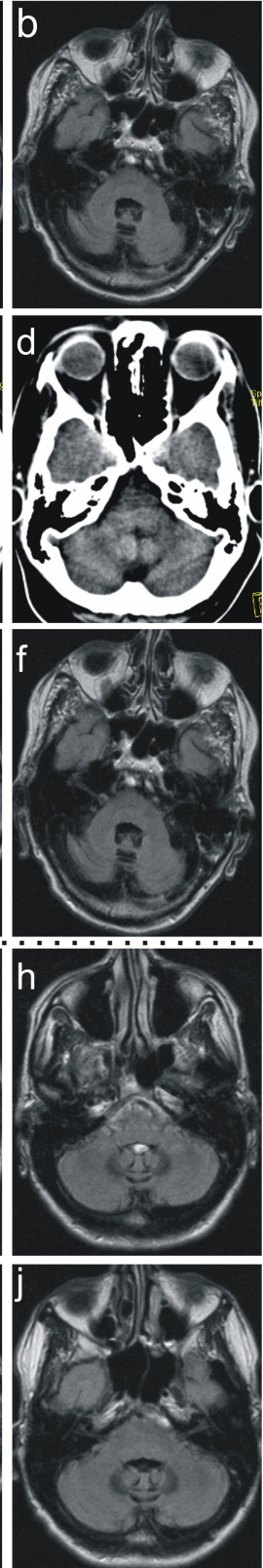
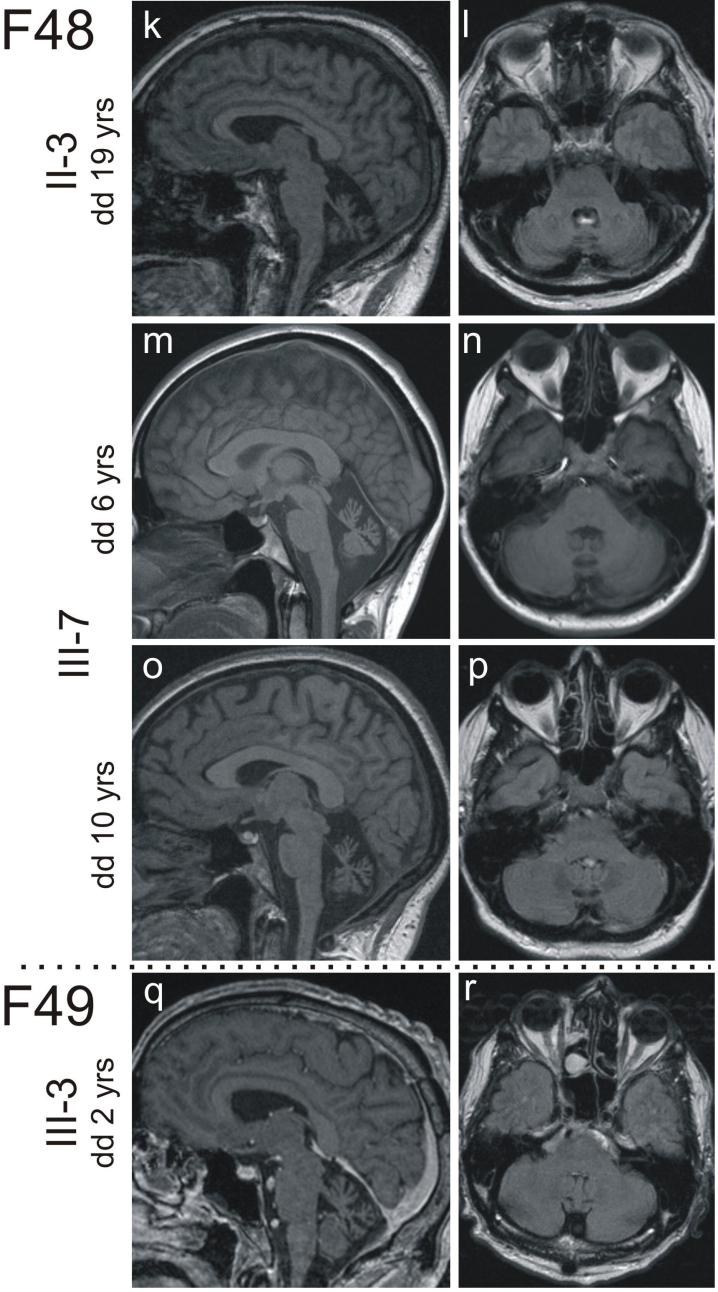